\title{
COMPARISON OF 0.5\% ROPIVACAINE WITH DEXMEDETOMIDINE AND 0.5\% BUPIVACAINE WITH DEXMEDETOMIDINE FOR EPIDURAL ANAESTHESIA IN LOWER ABDOMINAL AND LOWER LIMB SURGERIES
}

\author{
Ch. Srinivas Rao', M. Prasada Rao², Beera Gautham Kumar³, Kola Sujani4 \\ ${ }^{1}$ Associate Professor, Department of Anaesthesiology, Rajiv Gandhi Institute of Medical Sciences, Srikakulam. \\ ${ }^{2}$ Associate Professor, Department of Anaesthesiology, Rajiv Gandhi Institute of Medical Sciences, Srikakulam. \\ ${ }^{3}$ Post Graduate, Department of Anaesthesiology, Andhra Medical College, Visakhapatnam. \\ ${ }^{4}$ Registrar, Department of Anaesthesia, Manipal Hospitals, Visakhapatnam.
}

\section{ABSTRACT}

\section{BACKGROUND}

In view of the wider application of regional anaesthetic procedures in modern anaesthesia practice, there is a need for local anaesthetic with desirable properties like long duration of sensory blockade and lesser duration of motor paralysis; $\alpha$ - 2 adrenergic agonists have both analgesic and sedative properties when used as an adjuvant in regional anaesthesia. ${ }^{1-6}$ Dexmedetomidine is a highly selective $\alpha-2$ adrenergic agonist with an affinity eight times greater than that of clonidine.

\section{AIM}

To evaluate the clinical efficacy of $0.5 \%$ ropivacaine with dexmedetomidine by epidural route compared to $0.5 \%$ bupivacaine with dexmedetomidine by epidural route in patients undergoing lower abdominal and lower limb surgeries.

\section{MATERIALS AND METHODS}

In this study, 60 patients aged between 18-60 yrs. of either sex, belonging to ASA-I and II undergoing elective lower abdominal and lower limb surgeries were randomly divided into two groups. Group RD comprises of patients in whom $20 \mathrm{~mL}$ of $0.5 \%$ ropivacaine with $30 \mathrm{mcg}$. Dexmedetomidine was administered single shot epidurally. Group BD comprises of patients in whom $20 \mathrm{~mL}$ of $0.5 \%$ bupivacaine with $30 \mathrm{mcg}$. Dexmedetomidine was administered single shot epidurally.

\section{RESULTS}

Addition of dexmedetomidine as an adjuvant to both the groups has shortened the mean time of onset of both sensory and motor blockade. The time for two segmental regression in ropivacaine dexmedetomidine (RD) group is less than that of bupivacaine dexmedetomidine (BD) group, which is statistically significant. The mean time of onset of motor blockade is longer in group RD than that of the group BD, which is statistically highly significant. Duration of motor blockade in group BD is longer than that of group RD, which is statistically significant.

\section{CONCLUSION}

Bupivacaine with dexmedetomidine group had early onset of motor and sensory blockade with longer duration of motor blockade than that of ropivacaine with dexmedetomidine group. Group ropivacaine with dexmedetomidine had shorter mean duration of sensory and motor blockade, which has the advantage of early ambulation and stable hemodynamics with less cardiotoxicity, therefore making it more suitable for day care surgeries.

\section{KEYWORDS}

Dexmedetomidine, Epidural, 0.5\% Ropivacaine, 0.5\% Bupivacaine.

HOW TO CITE THIS ARTICLE: Ch. Srinivas Rao, Rao MP, Kumar BG, et al. Comparison of 0.5\% ropivacaine with dexmedetomidine and $0.5 \%$ bupivacaine with dexmedetomidine for epidural anaesthesia in lower abdominal and lower limb surgeries. J. Evolution Med. Dent. Sci. 2016;5(14):620-622, DOI: 10.14260/jemds/2016/141

\section{INTRODUCTION}

Various adjuvants can be added to local anaesthetics and administered for central neuraxial blockade. Sedation, stable haemodynamics and an ability to provide smooth and prolonged post-operative analgesia are the main desirable qualities of an adjuvant in neuraxial anaesthesia.

Financial or Other, Competing Interest: None.

Submission 04-01-2016, Peer Review 29-01-2016,

Acceptance 05-02-2016, Published 16-02-2016.

Corresponding Author:

Dr. Ch. Srinivas Rao,

Flat No. 4G, Rednam Alcazar,

Jail Road, Visakhapatnam,

Andhra Pradesh.

E-mail: srinivasrao719@gmail.com

DOI: $10.14260 /$ jemds/2016/141 $\alpha-2$ adrenergic agonists have both analgesic and sedative properties when used as an adjuvant in regional anaesthesia. ${ }^{1-6}$ Dexmedetomidine is a highly selective $\alpha-2$ adrenergic agonist with an affinity eight times greater than that of clonidine. There is no such study which has compared the dose equivalence of these drugs, but the observations of various studies have stated that the dose of Clonidine is 1.5-2 times higher than that of dexmedetomidine when used in epidural route. ${ }^{7-12}$ The anaesthetic and the analgesic requirements get reduced to a huge extent by the use of these two agents.

\section{MATERIALS AND METHODS}

This study was carried out in the Department of Anaesthesiology, Andhra Medical College, King George Hospital, Visakhapatnam, from December 2013 to August 2015. 
After the approval from the Hospital Ethical Committee, 60 patients aged between 18-60 yrs. of either gender belonging to ASA-I and II grades, undergoing elective lower abdominal and lower limb surgeries were randomly divided into two groups. After taking written informed consent from patients, they were subjected to Tuohy needle injection of $18 \mathrm{G}$ and given epidural anaesthesia.

\section{Group RD}

This group comprises of patients in whom $20 \mathrm{~mL}$ of $0.5 \%$ ropivacaine with $30 \mathrm{mcg}$. Dexmedetomidine was administered single shot epidurally.

\section{Group BD}

This group comprises of patients in whom $20 \mathrm{~mL}$ of $0.5 \%$ bupivacaine with $30 \mathrm{mcg}$. Dexmedetomidine was administered single shot epidurally.

Inclusion Criteria are ASA Grade-I and II physical status, aged between 18-60 years, of either sex undergoing elective lower abdominal and lower limb surgeries with surgical duration of 90-120 minutes. Exclusion criteria are patients not willing for the study, ASA Grade III and IV, cardiac patients, known sensitivity to local anesthetics, local infection at the site of injection, coagulopathy and congenital abnormalities of lower spine.

In the two groups the following were noted namely onset of sensory blockade at $\mathrm{T}_{10}$ level, maximum sensory block level achieved, time to attain maximum sensory block level, onset of motor blockade, 2 segment regression time, duration of motor block, time to sensory regression S1 from maximum sensory level, hemodynamic variables like systolic BP, diastolic BP, HR were recorded every $5 \mathrm{~min}$ until $15 \mathrm{~min}$ and at $15 \mathrm{~min}$ interval thereafter up to $60 \mathrm{~min}$ and then at $30 \mathrm{~min}$ interval till the end of surgery. Side effects like nausea, vomiting, bradycardia, hypotension, respiratory depression, dry mouth and shivering were noted in both groups.

Onset time of sensory blockade was taken from the completion of injection of study drug till the patient does not feel the pin prick. Onset time of motor blockade was taken from the completion of injection of study drug till the patient is unable to move the feet. The duration of motor blockade was taken from the completion of injection of study drug till motor block regresses to modified Bromage scale 1. The duration of sensory block was taken as the time of regression by two segments in the maximum block height, evaluated by pinprick.

A fall in blood pressure by more than $20 \%$ below the baseline value, even after intravenous fluids administration was managed by Inj. Mephenteramine IV given in titrated doses. If the pulse rate was less than $20 \%$ of baseline, Inj. Atropine $0.6 \mathrm{mg}$ IV was given. If respiratory rate was less than $10 / \mathrm{min}$, respiratory depression was diagnosed.

\section{RESULTS}

Addition of dexmedetomidine as an adjuvant to both the groups has shortened the mean time of onset of both sensory and motor blockade. The time for two segmental regression in Ropivacaine-Dexmedetomidine (RD) group is less than that of Bupivacaine-Dexmedetomidine (BD) group, which is statistically significant. Time for sensory regression to $\mathrm{S} 1$ from maximum sensory level (T6) is similar in both the groups. The mean time of onset of motor blockade is longer in group RD than that of the group $\mathrm{BD}$, which is statistically highly significant.
Duration of motor blockade in group BD is longer than that of group RD, which is statistically significant. Both the groups were similar in hemodynamic stability and side effects.

\begin{tabular}{|c|c|c|c|}
\hline & RD & BD & p value \\
\hline Age (yr) & $37.9 \pm 10.3$ & $35.7 \pm 10.5$ & $>0.05$ \\
\hline Height(cm) & $151.1 \pm 4.6$ & $150.8 \pm 4.7$ & $>0.05$ \\
\hline $\begin{array}{c}\text { Sensory onset to } \\
\text { T10(min) }\end{array}$ & $8.1 \pm 1.5$ & $7.8 \pm 1.3$ & $>0.05$ \\
\hline $\begin{array}{c}\text { Time to maximum } \\
\text { sensory level(min) }\end{array}$ & $13.1 \pm 2.1$ & $10.8 \pm 1.7$ & $>0.05$ \\
\hline $\begin{array}{c}\text { Time to Bromage } \\
\text { 3(min) }\end{array}$ & $14.1 \pm 2.0$ & $11.5 \pm 1.3$ & $<0.001^{*}$ \\
\hline $\begin{array}{c}\text { 2 segmental } \\
\text { sensory } \\
\text { regression(min) }\end{array}$ & $143.6 \pm 6.8$ & $156.4 \pm 8.3$ & $<0.05^{*}$ \\
\hline $\begin{array}{c}\text { Duration of motor } \\
\text { blockade(min) }\end{array}$ & $227.3 \pm 20.8$ & $265 \pm 23.4$ & $<0.05^{*}$ \\
\hline $\begin{array}{c}\text { Sensory regression } \\
\text { to S1 from } \\
\text { maximum sensory } \\
\text { level T6(min) }\end{array}$ & $264.3 \pm 13.9$ & $265 \pm 23.4$ & $>0.05$ \\
\hline \multicolumn{3}{|c|}{ Table 1: Demographic Data and Characteristic } \\
of Sensory and Motor Block
\end{tabular}

*significant, **highly significant

\section{STATISTICAL ANALYSIS}

At the end of the study, all the data was compiled and statistically analysed using diagrammatic representation, descriptive data presented as mean $\pm \mathrm{SD}$, continuous data analysed by paired or unpaired " $t$ " test. Probability value, $p$ $>0.05$ is not significant, $p<0.05$ is significant and $p<0.001$ is highly significant.

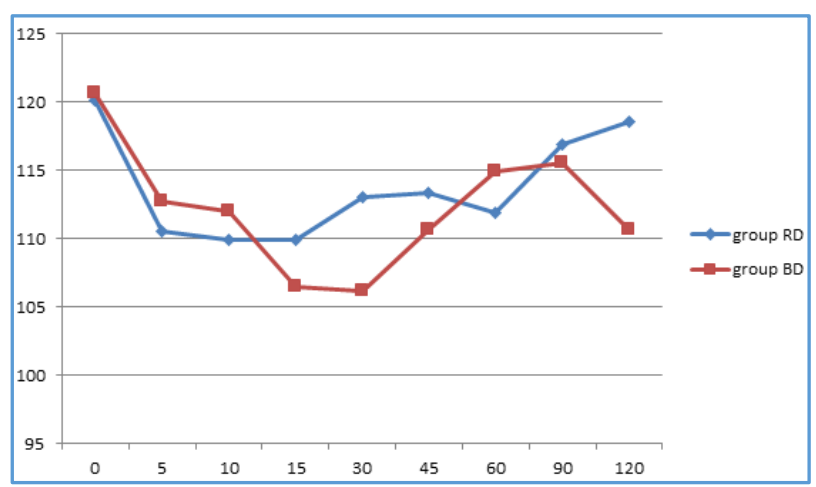

Graph 1: Mean Systolic Pressure of the Two Groups at Various Intervals of Time

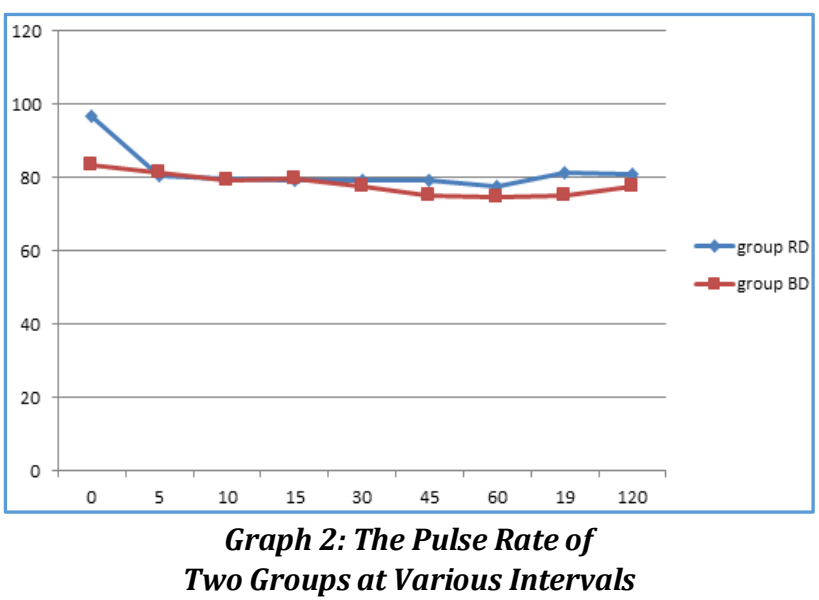




\section{DISCUSSION}

Ropivacaine, the recently introduced long-acting amide local anaesthetic derived from bupivacaine is claimed to have lesser cardiovascular effects being an S-enantiomer. Ropivacaine is said to be better in its cardiovascular profile as the patient can be revived from its cardiovascular side effects easily than when it occurs with bupivacaine.

Neuraxial anaesthesia and analgesia provide the required effects by inhibiting nociceptive transmission from peripheral to central neuronal systems, but their analgesic advantages might be limited by the short half-life of local anesthetics. Local anesthetics have to be given in larger doses to achieve the required analgesic and anaesthetic effects, however, with the risk of accompanied systemic neurotoxicity.

The addition of adjuvants like alpha- 2 adrenergic agonists, clonidine and dexmedetomidine can reduce the dose requirement and permit use of more diluted solutions for better analgesia and prevent the side-effects associated with larger volumes of local anesthetics. In this study, $30 \mathrm{mcg}$ dexmedetomidine was given to both the study groups to hasten the sensory and motor blockade.

Mantovalou. ${ }^{13}$ et al. 2008 compared the anaesthetic efficacy and safety of three local anaesthetic agents bupivacaine, ropivacaine and levobupivacaine. They concluded that ropivacaine presented a shorter duration of both sensory and motor block.

In a study by M.S. Sarvana. ${ }^{14}$ et al. 2013, dexmedetomidine not only provided early onset of sensory block, but also helped in achieving peak analgesic level in a shorter period. They compared the efficacy of dexmedetomidine to that of clonidine in spine surgeries and found that dexmedetomidine is a better adjuvant for providing early onset of maximum sensory block level.

Zaric D. 15 et al. in 1996 showed that motor blockade is less intense and of shorter duration with epidural ropivacaine compared with that of bupivacaine.

\section{CONCLUSION}

Bupivacaine with dexmedetomidine group had early onset of motor and sensory blockade with longer duration of motor blockade than that of ropivacaine with dexmedetomidine group. Group ropivacaine with dexmedetomidine had shorter mean duration of sensory and motor blockade, which has the advantage of early ambulation and stable hemodynamics with less cardiotoxicity, therefore making it more suitable for day care surgeries.

\section{REFERENCES}

1. Kamibayashi T, Maze M. Clinical uses of alpha-2 agonists. Anesthesiology 2000;93:1345-9.

2. Scafati A. Analgesia and alpha-2 agonists. Medens Rev 2004;4-7.

3. Mauro VA, Brandao ST. Clonidine and dexmedetomidine through epidural route for post-operative analgesia and sedation in a cholecystectomy. Rev Bras anesthesiol 2004;4:1-10.

4. Gabriel JS, Gordin V. Alpha-2 agonists in regional anaesthesia and analgesia. Curr Opin Anesthesiol 2001;14:751-3.

5. Hall JE, Uhrich TD, Barney JA. Sedative, amnestic and analgesic properties of small-dose dexmedetomidine infusions. Anesth Analg 2000;90:699-705.

6. Bucklin B, Eisenach JC, Tucker B. Pharmacokinetics and dynamic studies of intrathecal, epidural and intravenous dexmedetomidine. Anesthesiology; 1991;75(suppl):662.

7. Bischoff P, Kochs E. Alpha-2 agonists in anaesthesia and intensive medicine. Anesthesiol Intensivmed Notfallmed Schmerzther 1993;28:2-12.

8. Ribeiro RN, Nascimento JP. The use of dexmedetomidine in anesthesiology. Rev Bras Anesthesiol 2003;53:97-113.

9. Linde $\mathrm{H}$ e Mo. The clinical use of dexmedetomidine. Rev Bras Anesthesiol 2004;54:1-4.

10. Ebert TJ, Hall JE, Barney JA, et al. The effects of increasing plasma concentrations of dexmedetomidine in humans. Anesthesiology 2000;93:382-94.

11. Michael J Cousins, Bernadette T Veering. Epidural neural blockade 109 Chapter 8. Neural blockade in clinical anaesthesia and management of pain. Third edition; 1998;243-312.

12. David L Brown. Spinal, epidural and caudal anaesthesia. Chapter 42. Anesthesia Ronald D Miller; $5^{\text {th }}$ edition: 1491-98.

13. Zaric D, Nydahl PA, Philipson L. The effect of continuous lumbar epidural infusion of ropivacaine $(0.1 \%, 0.2 \%$, $0.3 \%$ ) and $0.25 \%$ bupivacaine on sensory and motor block. Reg Anesth 1996;21:14-25.

14. Mantouvalou M, Ralli S, Arnaoutoglou H. Comparison of ropivacaine, bupivacaine and levobupivacaine for lower abdominal surgery. Acta Anesth Belg 2008;59:65-71.

15. Saravana Babu MS, Anil Kumar Verma. Study of postop analgesia in spine surgeries, IJA 2013; 57:371-6. 